\title{
HER2+ and triple-negative phenotypes in invasive lobular carcinoma might have different specific biological features
}

\author{
Kadri Altundag ${ }^{1}$ (D) \\ Received: 29 April 2019 / Accepted: 10 May 2019 / Published online: 18 May 2019 \\ ○) Springer Science+Business Media, LLC, part of Springer Nature 2019
}

\section{Dear Editor,}

I want to congratulate Flores-Díaz et al. [1] in which they compared the differences in disease-free survival (DFS) and overall survival (OS) between invasive lobular carcinoma (ILC) and invasive ductal carcinoma (IDC) in Hispanic population with breast cancer (BC). They found that the ILC pathologic subtype negatively influenced DFS as an independent factor, but did not correlate with better OS compared with IDC. In the ILC pathologic subtype, $18 \%$ of all tumors had triple-negative (TN) or HER2+ phenotype. Interestingly, OS in TN and HER2+ patients in ILC subtype were significantly worse compared to TN and HER2+ patients in IDC subtype (54.2\% vs. $77.5 \%$ in TN phenotype, $74.4 \%$ vs. $90.6 \%$ in HER2+ phenotype). However, OS in hormone-sensitive patients in both subtypes were almost the same (89.4\% in ILC subtype, $91.3 \%$ in IDC subtype). These results might show that HER $2+$ and TN phenotypes in ILC subgroup might have different specific biological features which led to worse OS compared to OS in HER2+ and TN phenotypes in IDC subtypes. This issue merits further investigation.

\section{Compliance with ethical standards}

Conflict of interest The author declares that have no conflict of interest.

Ethical approval The manuscript complies with the Ethical Rules applicable for this journal. The manuscript complies with the current laws of the country in which they were performed.

Research involving human participants and/or animals This article does not contain any studies with human participants or animals performed by any of the authors.

\section{Reference}

1. Flores-Díaz D, Arce C, Flores-Luna L et al (2019) Impact of invasive lobular carcinoma on longterm outcomes in Mexican breast cancer patients. Breast Cancer Res Treat. https://doi.org/10.1007/ s10549-019-05234-8

Publisher's Note Springer Nature remains neutral with regard to jurisdictional claims in published maps and institutional affiliations.
Kadri Altundag

altundag66@yahoo.com

1 MKA Breast Cancer Clinic, Tepe Prime, Cankaya, 06800 Ankara, Turkey 